\title{
Development of form and function in the mammalian cochlea
}

\author{
Michael C Kelly and Ping Chen \\ Department of Cell Biology, Emory University, 615 Michael Street, Atlanta, GA 30322, United \\ States
}

\section{Abstract}

The cochlea possesses specialized features to receive sound signals and to resolve and convert the frequency and intensity components within each signal for auditory perception. This review It consists of precisely patterned and polarized sensory cells adorned with a highly specialized mechanotransduction apparatus for sensitivity and adaptation, and discrete nonsensory cellular networks for biochemical and mechanical support to drive an integrated cellular response and mechanotransduction. summarizes recent discoveries about the roles of FGF, Notch, and Hedgehog signaling and transcriptional factors in the differentiation and patterning of the auditory sensory organ, the Usher complex, and the planar cell polarity pathway in the formation and polarization of mechanotransduction component hair bundles, and the contribution of nonsensory cell networks in the stria vascularis and the sensory region toward the maturation of the mammalian cochlea.

\section{Introduction}

The cochlea is a fluid-filled compartment in the inner ear with a fluid partition that is critical for its mechanotransduction. It is divided into three chambers (scalae) through most of its length by a membrane-bound endolymph-filled column (scala media or cochlear duct) (Figure 1). The cochlear duct is flanked by the stria vascularis on the lateral side, and separated from the perilymphatic fluid of the scala vestibuli and the scala tympani by the Reissner's membrane and the flexible basilar membrane, respectively [1].

The mammalian auditory sensory organ, the organ of Corti, resides on the basilar membrane and typically comprises one row of inner hair cells (IHCs) and three rows of outer hair cells (OHCs) interdigitated with several types of morphologically distinct nonsensory supporting cells (Figure 1). Each hair cell has on its apical surface a set of stereocilia arranged into a ' $\mathrm{V}$ '-shaped bundle that accommodates the mechanotransduction channels and regulates their activity by directional bending. All the sensory hair cell bundles show precise and identical orientations with their vertices aligned, producing an ordered array of sensors endowed with directional sensitivity to mechanical stimulation [2]. The mechanical properties of the transduction apparatus in hair cells are graded along the longitudinal axis of the cochlea, tuning to a tonotopic movement of the basilar membrane for frequency resolution [3].

(C) 2009 Elsevier Ltd. All rights reserved.

Corresponding author: Chen, Ping (ping.chen@emory.edu). 
The hair cells and supporting cells of the organ of Corti, along with other epithelial cells of the cochlear duct, form tight junctions and distinct networks of gap junctions, leading to complete partition of the endolymph from the perilymph and formation of cellular syncytia. In contrast to the normal extracellular fluid composition of the perilymph, the endolymph has an unusually high $\mathrm{K}^{+}$concentration and generates an endocochlear potential of $+80 \mathrm{mV}$ across the epithelia lining the scala media that contributes to a large potential gradient of 140 $\mathrm{mV}$ in the sensory hair cells to drive currents across the mechanotransduction channels localized at the apical surface of hair cells, in response to the displacement of the basilar membrane and the deflection of stereocilia [4,5]. Cellular syncytia within the cochlear duct couple transfer of signaling, ion, and nutrient molecules for homeostasis and mechanoelectrical responses [6].

These structural features represent some of the most extraordinary examples of cellular patterning, polarity, and organization that contribute to the exquisite sensitivity of the mammalian cochlea. The development of these structural features is the subject of this review.

\section{Specification of the sensory lineage and cellular patterning in the cochlea}

The cochlea develops from a tubular outpocketing at the ventral-medial region of the otic vesicle, which originates from the otic placode, a patch of ectodermal cells near the hindbrain. The formation of the complex structure of the cochlea from this relatively simple epithelium is orchestrated by a regulatory network that controls successive cell differentiation and division events in a coordinated manner (Figure 2) [7,8].

The specification of the sensory lineage, or the prosensory domain, in the cochlea involves converging pathways of fibroblast growth factor (FGF) and Notch signaling, and a cascade of transcriptional factors [8,9]. A transcriptional factor, Sox2, is necessary for the development of the prosensory domain. The Notch pathway component Jagged1 appears to be important for inducing the expression of Sox 2 and endowing cells with the competence to become sensory cells $\left[10^{\bullet}\right]$. The mammalian FGF signaling pathway acts through a large number of FGF ligands and four FGF receptors (FGFR), of which many are involved in key developmental decisions for the formation of the cochlea [8]. In particular, FGF20 signaling through the FGF receptor 1 (FGFR1) is important for making the prosensory region competent and loss of either of these components leads to a severe reduction in the number of sensory cells $[11 \bullet \bullet]$. Conversely, the Hedgehog and Lmx1a pathways appear to act to restrict the expression of Sox 2 and define the boundaries of the prosensory domain $[12,13 \bullet]$.

The specification of the prosensory domain is coupled to a synchronized cell cycle withdrawal. In addition to cyclindependent kinase (CDK) inhibitors p27/Kip1 and p19/Ink4d and the pocket protein $\mathrm{pRb}$ [14], CDK inhibitors p21/Cip1 and p57/Kip2 have been shown to be important in carrying out the termination of mitosis and maintaining of their postmitotic state $[14,15]$. The processes of differentiation and patterning occur subsequently within the postmitotic prosensory domain to create the final array of cell types and are regulated by some of the pathways mentioned earlier. It is known that the Notch pathway specifies hair cell versus supporting cell fate in the organ of Corti, and a transcriptional 
factor, Math1, is required for hair cell differentiation [8]. Further progress is being made in understanding the induction of hair cell differentiation and specification of individual supporting cell types. Sox 2 and Prox 1, which are expressed early and act to specify the prosensory domain, play roles later in inhibiting Math1 and its downstream targets such as Gfil for the differentiation of supporting cells $[10 \bullet, 16]$. Furthermore, FGF signaling acts in a primarily Notch-independent manner to determine the differentiation of the pillar cells, a specific type of supporting cells, that reside between the row of IHCs and the first row of $\mathrm{OHC}$ and among the first row of OHCs [17•]. FGF8 from developing IHCs induces the neighboring FGF receptor $3^{+}$(FGFR3) cells to differentiate into pillar cells, under the surveillance of FGF signaling inhibitor Sprouty 2 that restricts the adaptation of pillar cell fate by additional cells (Figure 2) $[18,19 \bullet \bullet, 20]$.

Within the cochlea, hair cells along the longitudinal axis of the cochlea have graded mechanoelectrical properties that allow them to be tuned to respond maximally to a progression of frequencies depending on their location along the length of the cochlea. In addition, IHCs differ biologically and functionally from OHCs [5,21•]. It is known that the acquisition and maturation of mechanoelectric transduction in hair cells occur in a gradient from the base to the apex of the cochlea [3,22], and that IHCs differentiate prior to OHCs [7]. However, the mechanisms regulating the formation of hair cells with differential functional and mechanoelectric properties remain unknown.

\section{Formation of uniformly oriented hair bundles in the cochlea}

Cell type specification leads to terminal morphogenesis of hair cells and supporting cells. One conspicuous morphogenetic event is the formation of a polarized stereociliary bundle, or hair bundle, on the apical surface of each hair cell. During terminal differentiation, microvilli-derived and actin-filled stereocilia achieve graded height and are arranged into a 'V'-shaped staircase composed of several rows of stereocilia with taller stereocilia at the outmost row and the tallest stereocilium at the vertex of the ' $\mathrm{V}$ '- shaped bundle. All of the intrinsically polarized hair cells are uniformly oriented with the vertices of the ' $V$ '-shaped hair bundles aligned in the central-to-peripheral, or the medial-to-lateral, direction of the cochlea, showcasing a type of tissue polarity that is parallel to the plane of the epithelial sheet and known as planar cell polarity (PCP) [2]. The PCP of the organ of Corti is integrally related to mechanotransduction as hair bundle deflection toward or away from the vertex of the hair bundle along the axis of planar polarity opens and closes, respectively, cation channels that are mechanically gated by the interstereocilia links between rows of the stereocilia and are localized at the sites of attachment to shorter stereocilia [23••].

The precise and coordinated polarity of hair bundles in the cochlea is a morphogenetic readout of a complex genetic pathway that regulates PCP in many tissues. The vertebrate PCP pathway includes a core set of proteins such as Vang-like (Vangl), Prickle (Pk), Frizzled (Fzd), Dishevelled (Dvl), Protocadherin Celsr1, Scribbled 1 (Scrb1), and protein tyrosine kinase 7 (PTK7) or colon carcinoma kinase-4 (CCK-4) [24]. Some of these proteins are asymmetrically localized to one edge of the apical cortex of the cells and display polarized membrane association along the axis of PCP, which presumably coordinates the polarization of cytoskeletal elements in cells across the entire organ of Corti $[2,25 \bullet, 26,27 \bullet \bullet]$. 
The molecular mechanisms underlying the asymmetric partitioning of core PCP proteins appear to involve both selective targeting of core proteins directly $[28,29,30]$ and protein degradation machineries, such as ubiquitin ligase Smurf2, for proteasome-mediated protein degradation to restrict the retention of PCP proteins to a specific edge of the apical cellular cortex $[27 \bullet \bullet]$.

The coordinated orientation of all of the cells across the organ of Corti requires global directional cues that direct asymmetric partitioning of core PCP proteins. Among the best candidates are members of the Wnt family morphogens, because the Wnt receptor Fzd and Wnt coreceptors [31] have essential roles in PCP signaling. One member of the Wnt family, Wnt5a, is important for PCP regulation of the cochlea [32]. An additional gradient mechanism, comprising two atypical cadherins, Dachsous (Ds) and Fat (Ft), and a type II Golgi-localized membrane protein, Four-joined (Fj), has also been proposed to set up an activity gradient of the $\mathrm{Ds} / \mathrm{Ft} / \mathrm{Fj}$ module across the tissue that biases Fzd activity within individual cells [33]. Indeed, mouse Fat4 functions in PCP regulation in the cochlea [34]. However, the exact role of the $\mathrm{Ds} / \mathrm{Ft} / \mathrm{Fj}$ module in the cochlea awaits further investigation.

Genetic studies have also identified an essential component of the machinery that builds the polarized structure of the hair bundle. Usher syndrome (USH) is the most frequent cause of hereditary deaf-blindness in humans [35]. Genetic, cellular, and molecular studies of USH genes have illustrated the requirement for USH complex in the making of key elements of the hair bundle that are crucial for mechanotransduction. Individual stereocilia within a hair bundle are held together by multiple extracellular linkages and serve a mechanosensory function by pivoting at their bases in response to the movement of fluid across them, and the hair bundle in each hair cell moves as one constrained unit ensuring concerted gating of transduction channels [36]. Several USH proteins regulate the length of stereocilia and make up the links within the hair bundle. MyoVIIa (USH1B) regulates stereocilia length by inhibiting the length promoting activity of MyoXV and whirlin (USH2D) [37]. Vlgr1 (USH2C) is an important director of the interstereocilia ankle-link near the tapered base of stereocilia [38,39]. Cadherin 23 (Cdh23) (USH1D) and Protocadherin 15 (Pcdh15) (USH1F) form the tip-links that connect neighboring stereocilia at their tips [40••]. Harmonin (USH1C) as well as MAGI-1 may relay the interstereocilia links to the cytoskeletal network as intracellular binding partners of $\mathrm{Cdh} 23[41 \bullet]$.

The PCP pathway is obligated to provide direction to the machinery that builds the polarized structure of the hair bundle. A candidate molecular link between PCP signaling and the building machinery for hair bundles was recently identified $[42,43 \bullet \bullet, 44]$. The cochlear hair bundle contains transiently a single microtubule-rich primary cilium, the kinocilium, that is eccentrically positioned at the vertex of the ' $\mathrm{V}$ '-shaped bundle. In the absence of kinociliary genes, hair bundles become circular without affecting the asymmetric partitioning of core PCP proteins, indicating a role for kinociliary genes downstream of core PCP proteins in providing direction for hair bundle morphogenesis [43••]. However, a direct interaction between kinociliary genes and the USH complex has yet to be demonstrated. 


\section{Networks of nonsensory cells support functional maturation of the cochlea}

The functional maturation of the cochlea relies not only on the differentiation of hair cells and the formation of coordinately polarized hair bundles, but also on the formation of distinct networks of nonsensory cells that line the cochlear duct. In particular, the differentiation and proper organization of nonsensory cells on the lateral wall of the cochlea and within the organ of Corti are essential for, respectively, the endocochlear potential and the mechanical properties of the organ of Corti that are key to the sensitivity of the cochlea.

The stria vascularis adjacent to the spiral ligament on the lateral wall of the cochlea (Figure 1B) contributes to the distinct composition of the endolymphatic fluid that is high in $\mathrm{K}^{+}$and low in $\mathrm{Na}^{+}$and the generation of endocochlear potential to drive mechanotransduction [6]. $\mathrm{K}^{+}$secretion and transport through the stria vascularis requires differential expressions of several $\mathrm{K}^{+}$channels in various compartments of the stria vascularis and $\mathrm{ClCKa} / \mathrm{ClC}-\mathrm{Kb} \mathrm{Cl}^{-}$ channels [45]. The differentiation of individual stria vascularis epithelial cell types involves estrogen-related receptor b/NR3B2 [46••], and the development of the full complement of cells in the stria vascularis and spiral ligament is critical for the generation of endocochlear potential [47]. Furthermore, proper cellular connections among the constituent cells are essential for stria vascularis function. The transport of $\mathrm{K}^{+}$through the stria vascularis into the endolymph depends critically on the separation of individual domains of the stria vascularis and the syncytium formed within each domain through tight junctions and gap junctions, respectively [48]. Hearing loss in tight junction protein Claudin11 or gap junction subunits Connexin 26 and Connexin 30 mutants coincides with the decrease or disappearance of endocochlear potential $[49,50]$.

The differentiation of nonsensory cells in the organ of Corti is also required for the functional maturation of the cochlea. The nonsensory supporting cells have long cellular processes and form tight and adherens junctions among each other and with hair cells at the apical surfaces, forming a tightly sealed barrier between the endolymphatic fluid in the lumen and the perilymph in the basolateral domain. The maturation of supporting cells also helps to define the mechanical property of the organ of Corti, which is intimately related to interpretations of the movement of the basilar membrane. Furthermore, supporting cells during maturation form a syncytium through gap junctions that mediate biochemical coupling of signaling and ion molecules [51,52], and transfer of nutrients across the sensory epithelium for the maturation, survival, and function of the organ of Corti [53•].

\section{Conclusions}

Recent advances have identified the genetic pathways regulating the differentiation of individual cell types within the sensory and the stria vascularis regions of the cochlea; the formation and coordinated polarization of hair bundles; and the establishment of distinct cellular networks for endocochlear potential generation and for coupling electrical and biochemical activities and nutrient transfer. Future studies aiming to further illustrate the molecular details of these regulations will not only reveal the complex pathways that coordinate to allow the generation and maturation of a functional cochlea, but also provide 
valuable insights into fundamental questions in developmental biology, cell biology, and physiology.

\section{Acknowledgments}

We would like to thank Dr P Rida for helpful comments on the manuscript and Harrison Han for proof reading the manuscript. Figure 1B and 1C were modified from drawings by Drs X Lin [54] and P Rida [2], respectively. Some of the studies cited in the article are supported by NIH research grants to PC (RO1 DC005213 and DC007423).

\section{References and recommended reading}

Papers of particular interest, published within the period of review, have been highlighted as:

- of special interest

$\bullet$ of outstanding interest

1. Dallos, P.; Popper, AN.; Fay, RR., editors. Springer Handbook of Auditory Research. Vol. 8. New York: Springer; 1996.

2. Rida PC, Chen P. Line up and listen: planar cell polarity regulation in the mammalian inner ear. Semin Cell Dev Biol. 2009

3. Lelli A, Asai Y, Forge A, Holt JR, Geleoc GS. Tonotopic gradient in the developmental acquisition of sensory transduction in outer hair cells of the mouse cochlea. J Neurophysiol. 2009; 101:29612973. [PubMed: 19339464]

4. Muller U. Cadherins and mechanotransduction by hair cells. Curr Opin Cell Biol. 2008; 20:557566. [PubMed: 18619539]

5. Hudspeth AJ. Making an effort to listen: mechanical amplification in the ear. Neuron. 2008; 59:530-545. [PubMed: 18760690]

6. Wangemann P. Supporting sensory transduction: cochlear fluid homeostasis and the endocochlear potential. J Physiol. 2006; 576:11-21. [PubMed: 16857713]

7. Kelly M, Chen P. Shaping the mammalian auditory sensory organ by the planar cell polarity pathway. Int J Dev Biol. 2007; 51:535-547. [PubMed: 17891715]

8. Kelley MW. Cellular commitment and differentiation in the organ of Corti. Int J Dev Biol. 2007; 51:571-583. [PubMed: 17891718]

9. Abello G, Alsina B. Establishment of a proneural field in the inner ear. Int J Dev Biol. 2007; 51:483-493. [PubMed: 17891711]

10. Dabdoub A, Puligilla C, Jones JM, Fritzsch B, Cheah KS, Pevny LH, Kelley MW. Sox2 signaling in prosensory domain specification and subsequent hair cell differentiation in the developing cochlea. Proc Natl Acad Sci U S A. 2008; 105:18396-18401. [PubMed: 19011097] This study looks further into the role of the transcription factor Sox 2 in prosensory region development of the organ of Corti and places it downstream of Notch signaling. Like Notch signaling, Sox 2 has an early prosensory inductive expression and a later mutually repressive interaction with the hair cell differentiation factor Atoh1.

11. Hayashi T, Ray CA, Bermingham-McDonogh O. Fgf20 is required for sensory epithelial specification in the developing cochlea. J Neurosci. 2008; 28:5991-5999. [PubMed: 18524904] The authors used an FGF receptor inhibitor or an antibody against FGF20 and duplicated the cochlear phenotypes observed in FGFR1 knockout mice. The authors concluded that FGF signaling through FGF20 and FGFR1 is required for prosensory specification.

12. Nichols DH, Pauley S, Jahan I, Beisel KW, Millen KJ, Fritzsch B. Lmx1a is required for segregation of sensory epithelia and normal ear histogenesis and morphogenesis. Cell Tissue Res. 2008; 334:339-358. [PubMed: 18985389]

13. Driver EC, Pryor SP, Hill P, Turner J, Ruther U, Biesecker LG, Griffith AJ, Kelley MW. Hedgehog signaling regulates sensory cell formation and auditory function in mice and humans. $\mathrm{J}$ Neurosci. 2008; 28:7350-7358. [PubMed: 18632939] Using a mutant for Hedgehog (HH) 
downstream signaling component GLI3, as well as in vitro gain and loss of function, the authors show that HH signaling is important for defining the size of the sensory domain and that it can regulate the expression of prosensory domain markers such as Sox2.

14. Liu Z, Zuo J. Cell cycle regulation in hair cell development and regeneration in the mouse cochlea. Cell Cycle. 2008; 7:2129-2133. [PubMed: 18635955]

15. Laine H, Doetzlhofer A, Mantela J, Ylikoski J, Laiho M, Roussel MF, Segil N, Pirvola U. p19(Ink4d) and p21(Cip1) collaborate to maintain the postmitotic state of auditory hair cells, their codeletion leading to DNA damage and p53-mediated apoptosis. J Neurosci. 2007; 27:1434-1444. [PubMed: 17287518]

16. Kirjavainen A, Sulg M, Heyd F, Alitalo K, Yla-Herttuala S, Moroy T, Petrova TV, Pirvola U. Prox1 interacts with Atoh1 and Gfi1, and regulates cellular differentiation in the inner ear sensory epithelia. Dev Biol. 2008; 322:33-45. [PubMed: 18652815]

17. Doetzlhofer A, Basch ML, Ohyama T, Gessler M, Groves AK, Segil N. Hey2 regulation by FGF provides a Notch-independent mechanism for maintaining pillar cell fate in the organ of Corti. Dev Cell. 2009; 16:58-69. [PubMed: 19154718] The authors mapped out the complex signaling involved in the differentiation of pillar cells.

18. Hayashi T, Cunningham D, Bermingham-McDonogh O. Loss of Fgfr3 leads to excess hair cell development in the mouse organ of Corti. Dev Dyn. 2007; 236:525-533. [PubMed: 17117437]

19. Jacques BE, Montcouquiol ME, Layman EM, Lewandoski M, Kelley MW. Fgf8 induces pillar cell fate and regulates cellular patterning in the mammalian cochlea. Development. 2007; 134:30213029. [PubMed: 17634195] The investigators report that developing inner hair cells secrete FGF8 and direct the differentiation of pillar cells via FGFR3. A negative regulator for FGF signaling, Sprouty 2, further restricts the response of FGFR3-expressing cells.

20. Puligilla C, Feng F, Ishikawa K, Bertuzzi S, Dabdoub A, Griffith AJ, Fritzsch B, Kelley MW. Disruption of fibroblast growth factor receptor 3 signaling results in defects in cellular differentiation, neuronal patterning, and hearing impairment. Dev Dyn. 2007; 236:1905-1917. [PubMed: 17557302]

21. Dallos P, Wu X, Cheatham MA, Gao J, Zheng J, Anderson CT, Jia S, Wang X, Cheng WH, Sengupta S, et al. Prestin-based outer hair cell motility is necessary for mammalian cochlear amplification. Neuron. 2008; 58:333-339. [PubMed: 18466744] The authors used a Prestin mutant strain that does not cause general defects in the cochlea to conclude that Prestin-based electromotility is required for cochlear amplification.

22. Waguespack J, Salles FT, Kachar B, Ricci AJ. Stepwise morphological and functional maturation of mechanotransduction in rat outer hair cells. J Neurosci. 2007; 27:13890-13902. [PubMed: 18077701]

23. Beurg M, Fettiplace R, Nam JH, Ricci AJ. Localization of inner hair cell mechanotransducer channels using high-speed calcium imaging. Nat Neurosci. 2009; 12:553-558. [PubMed: 19330002] Using high-speed confocal imaging of calcium entry during hair bundle stimulation, the authors show that calcium signals are much larger and faster in the second and third rows than in the tallest first row within individual hair bundles. In combination with theoretical simulations, the authors conclude that there are no functional mechanically sensitive transducer channels in the first tallest row of stereocilia and about two channels per stereocilium in the two other rows. Since mechanosensitive channels are gated by tip-links formed between two neighboring rows of stereocilia of differential height, the study implies that the mechanosensitive channels are present at the attachment to the shorter stereocilium of the tip-links, or the bottom of the tip-links.

24. Chacon-Heszele MF, Chen P. Mouse models for dissecting vertebrate planar cell polarity signaling in the inner ear. Brain Res. 2009; 1277:130-140. [PubMed: 19232327]

25. Deans MR, Antic D, Suyama K, Scott MP, Axelrod JD, Goodrich LV. Asymmetric distribution of prickle-like 2 reveals an early underlying polarization of vestibular sensory epithelia in the inner ear. J Neurosci. 2007; 27:3139-3147. [PubMed: 17376975] Using antibodies and tagged proteins, the authors show uniform and asymmetric membrane association of Prickle-like 2 in the vestibular sensory epithelia, regardless of the opposite orientation of sensory hair cells. The study implicates additional mechanisms independent of Prickle-like 2 for planar cell polarization in the vestibular sensory organs. 
26. Etheridge SL, Ray S, Li S, Hamblet NS, Lijam N, Tsang M, Greer J, Kardos N, Wang J, Sussman DJ, et al. Murine dishevelled 3 functions in redundant pathways with dishevelled 1 and 2 in normal cardiac outflow tract, cochlea, and neural tube development. PLoS Genet. 2008; 4:e1000259. [PubMed: 19008950]

27. Narimatsu M, Bose R, Pye M, Zhang L, Miller B, Ching P, Sakuma R, Luga V, Roncari L, Attisano L, et al. Regulation of planar cell polarity by Smurf ubiquitin ligases. Cell. 2009; 137:295-307. [PubMed: 19379695] This comprehensive study demonstrates that the ubiquitin ligase Smurf can form a signaling complex with other known PCP proteins such as Dv12 and Par-6 and this signaling complex may regulate the asymmetric degradation of Prickle1 within individual cells. Smurf mutants have planar cell polarity phenotypes in neurulation and the cochlea.

28. Gagliardi M, Piddini E, Vincent JP. Endocytosis: a positive or a negative influence on Wnt signalling? Traffic. 2008; 9:1-9. [PubMed: 17908284]

29. Shimada Y, Yonemura S, Ohkura H, Strutt D, Uemura T. Polarized transport of Frizzled along the planar microtubule arrays in Drosophila wing epithelium. Dev Cell. 2006; 10:209-222. [PubMed: 16459300]

30. Strutt H, Strutt D. Differential stability of flamingo protein complexes underlies the establishment of planar polarity. Curr Biol. 2008; 18:1555-1564. [PubMed: 18804371]

31. Yamamoto S, Nishimura O, Misaki K, Nishita M, Minami Y, Yonemura S, Tarui H, Sasaki H. Cthrc1 selectively activates the planar cell polarity pathway of Wnt signaling by stabilizing the Wnt-receptor complex. Dev Cell. 2008; 15:23-36. [PubMed: 18606138]

32. Qian D, Jones C, Rzadzinska A, Mark S, Zhang X, Steel KP, Dai X, Chen P. Wnt5a functions in planar cell polarity regulation in mice. Dev Biol. 2007; 306:121-133. [PubMed: 17433286]

33. Strutt D. The planar polarity pathway. Curr Biol. 2008; 18:R898-R902. [PubMed: 18957230]

34. Saburi S, Hester I, Fischer E, Pontoglio M, Eremina V, Gessler M, Quaggin SE, Harrison R, Mount R, McNeill H. Loss of Fat4 disrupts PCP signaling and oriented cell division and leads to cystic kidney disease. Nat Genet. 2008; 40:1010-1015. [PubMed: 18604206]

35. Leibovici MSSPC. Mouse models for human hereditary deafness. Curr Top Dev Biol. 2008; 84:385-429. [PubMed: 19186249]

36. Kozlov AS, Risler T, Hudspeth AJ. Coherent motion of stereocilia assures the concerted gating of hair-cell transduction channels. Nat Neurosci. 2007; 10:87-92. [PubMed: 17173047]

37. Prosser HM, Rzadzinska AK, Steel KP, Bradley A. Mosaic complementation demonstrates a regulatory role for myosin VIIa in actin dynamics of stereocilia. Mol Cell Biol. 2008; 28:17021712. [PubMed: 18160714]

38. Michalski N, Michel V, Bahloul A, Lefevre G, Barral J, Yagi H, Chardenoux S, Weil D, Martin P, Hardelin JP, et al. Molecular characterization of the ankle-link complex in cochlear hair cells and its role in the hair bundle functioning. J Neurosci. 2007; 27:6478-6488. [PubMed: 17567809]

39. Yagi H, Tokano H, Maeda M, Takabayashi T, Nagano T, Kiyama H, Fujieda S, Kitamura K, Sato M. Vlgr1 is required for proper stereocilia maturation of cochlear hair cells. Genes Cells. 2007; 12:235-250. [PubMed: 17295842]

40. Kazmierczak P, Sakaguchi H, Tokita J, Wilson-Kubalek EM, Milligan RA, Muller U, Kachar B. Cadherin 23 and protocadherin 15 interact to form tip-link filaments in sensory hair cells. Nature. 2007; 449:87-91. [PubMed: 17805295] Using antibodies against subdomains of Cadherin 23 and Protocadherin 15, the authors show that the two molecules are localized to complementary regions of the tip-link. Biochemical analysis further demonstrates that Cadherin 23 and Protocadherin 15 can form filaments with structural similarity to tip-links.

41. Xu Z, Peng AW, Oshima K, Heller S. MAGI-1, a candidate stereociliary scaffolding protein, associates with the tip-link component cadherin 23. J Neurosci. 2008; 28:11269-11276. [PubMed: 18971469] Using a yeast two-hybrid assay, the authors identified new components of the stereocilia tip-link complex involved in auditory mechanotransduction. The authors further showed that a new candidate MAGI-1 appears to interact with the hair cell specific isoform of Cadherin 23. They also provided evidence to support that MAGI-1 may be the dominant scaffolding adapter in the stereociliary tip-links.

42. Jones C, Chen P. Primary cilia in planar cell polarity regulation of the inner ear. Curr Top Dev Biol. 2008; 85:197-224. [PubMed: 19147007] 
43. Jones C, Roper VC, Foucher I, Qian D, Banizs B, Petit C, Yoder BK, Chen P. Ciliary proteins link basal body polarization to planar cell polarity regulation. Nat Genet. 2008; 40:69-77. [PubMed: 18066062] This study illustrated a requirement for ciliary genes in intrinsic polarity of sensory hair cells and demonstrated a role for ciliary genes downstream of membrane-associated core PCP proteins.

44. Ross AJ, May-Simera H, Eichers ER, Kai M, Hill J, Jagger DJ, Leitch CC, Chapple JP, Munro PM, Fisher S, et al. Disruption of Bardet-Biedl syndrome ciliary proteins perturbs planar cell polarity in vertebrates. Nat Genet. 2005; 37:1135-1140. [PubMed: 16170314]

45. Rickheit G, Maier H, Strenzke N, Andreescu CE, De Zeeuw CI, Muenscher A, Zdebik AA, Jentsch TJ. Endocochlear potential depends on Cl-channels: mechanism underlying deafness in Bartter syndrome IV. EMBO J. 2008; 27:2907-2917. [PubMed: 18833191]

46. Chen J, Nathans J. Estrogen-related receptor beta/NR3B2 controls epithelial cell fate and endolymph production by the stria vascularis. Dev Cell. 2007; 13:325-337. [PubMed: 17765677] The authors show that the orphan nuclear receptor is specifically expressed in the stria vascularis marginal cells and that the marginal cells in NR3B2 mutant animals are partially transformed and do not express the channels necessary for ion transport. Systematic gene expression analysis further identified a set of genes that may play a role in the development and function of the stria vascularis.

47. Trowe MO, Maier H, Schweizer M, Kispert A. Deafness in mice lacking the T-box transcription factor Tbx18 in otic fibrocytes. Development. 2008; 135:1725-1734. [PubMed: 18353863]

48. Nin F, Hibino H, Doi K, Suzuki T, Hisa Y, Kurachi Y. The endocochlear potential depends on two $\mathrm{K}^{+}$diffusion potentials and an electrical barrier in the stria vascularis of the inner ear. Proc Natl Acad Sci U S A. 2008; 105:1751-1756. [PubMed: 18218777]

49. Cohen-Salmon M, Regnault B, Cayet N, Caille D, Demuth K, Hardelin JP, Janel N, Meda P, Petit C. Connexin30 deficiency causes instrastrial fluid-blood barrier disruption within the cochlear stria vascularis. Proc Natl Acad Sci U S A. 2007; 104:6229-6234. [PubMed: 17400755]

50. Jin Z, Ulfendahl M, Jarlebark L. Spatiotemporal loss of K+ transport proteins in the developing cochlear lateral wall of guinea pigs with hereditary deafness. Eur J Neurosci. 2008; 27:145-154. [PubMed: 18093167]

51. Beltramello M, Piazza V, Bukauskas FF, Pozzan T, Mammano F. Impaired permeability to Ins $(1,4,5) \mathrm{P} 3$ in a mutant connexin underlies recessive hereditary deafness. Nat Cell Biol. 2005; 7:63-69. [PubMed: 15592461]

52. Zhang Y, Tang W, Ahmad S, Sipp JA, Chen P, Lin X. Gap junction-mediated intercellular biochemical coupling in cochlear supporting cells is required for normal cochlear functions. Proc Natl Acad Sci U S A. 2005; 102:15201-15206. [PubMed: 16217030]

53. Chang Q, Tang W, Ahmad S, Zhou B, Lin X. Gap junction mediated intercellular metabolite transfer in the cochlea is compromised in connexin30 null mice. PLoS ONE. 2008; 3:e4088. [PubMed: 19116647] The authors show that glucose transfer within the cochlea is compromised in Connexin 30 null mice, implicating a novel mechanism for the role of gap junctions in the cochlea.

54. Huang D, Chen P, Chen S, Nagura M, Lim DJ, Lin X. Expression patterns of aquaporins in the inner ear: evidence for concerted actions of multiple types of aquaporins to facilitate water transport in the cochlea. Hear Res. 2002; 165:85-95. [PubMed: 12031518] 

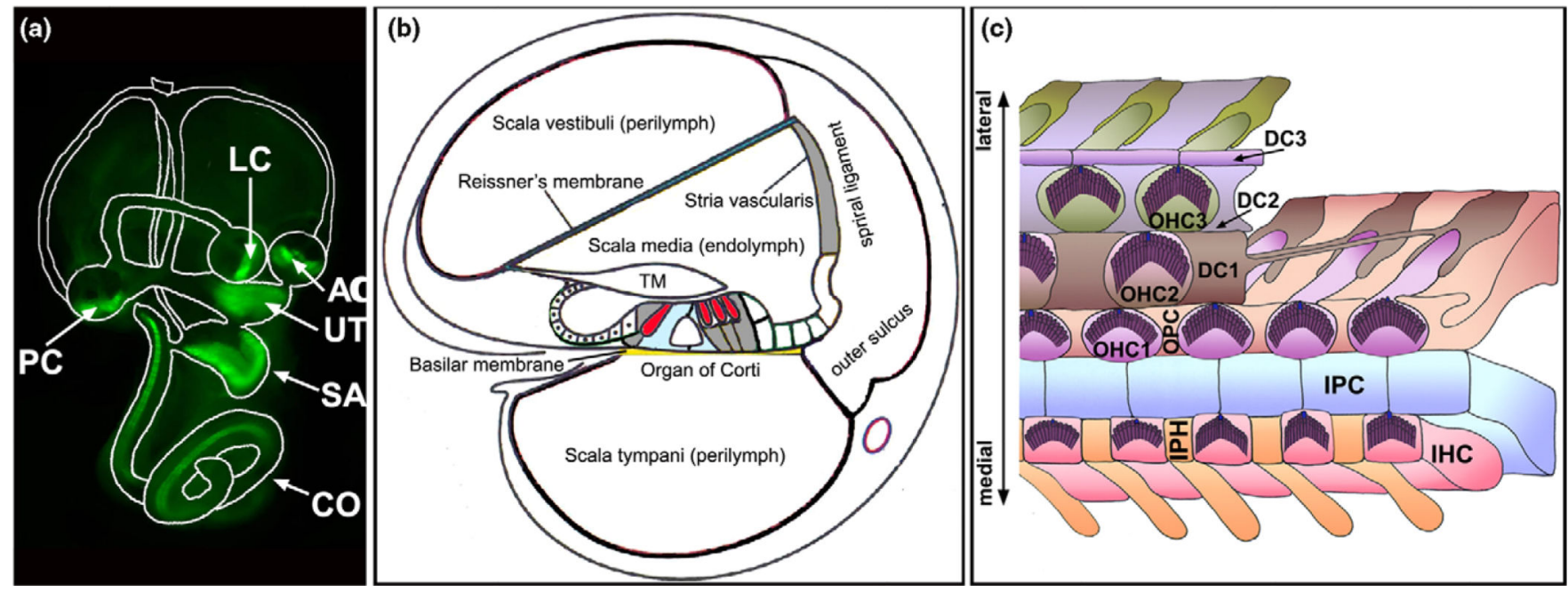

Figure 1.

The cochlea. (A) The inner ear consists of the cochlea (CO) and the vestibule. The cochlea has one sensory organ, the organ of Corti, which is marked by green fluorescent protein (green). The vestibule has five sensory organs: the maculae of the saccule (SA), the utricle (UT), and three cristae (AC, PC, and LC) that are also marked by green fluorescent protein (green). (B) A diagram of the cross-section of the cochlea, illustrating its three chambers and partitioning of the endolymphatic and perilymphatic fluids. The scala vestibule and scala tympani are filled with the perilymph while the scala media is filled with the endolymph. The stria vascularis contributes significantly to the unusual ion content of the endolymph. TM: tectorial membrane. The sensory hair cells are shown in red. (C) A schematic diagram of the whole-mount organ of Corti. In the organ of Corti, the inner (IHCs) and outer hair cells (OHCs) are interdigitated with several types of distinct nonsensory supporting cells: the inner phalangeal cells (IPHs), inner pillar cells (IPCs), outer pillar cells (OPCs), and three rows of Deiters' cells (DC1-DC3s). A single kinocilium (blue) and numerous stereocilia (purple) constitute a ' $\mathrm{V}$ '-shaped hair bundle on the apical surface of each nascent hair cell. All of the ' $V$ '-shaped hair bundles are uniformly aligned, showing a distinctive PCP. 


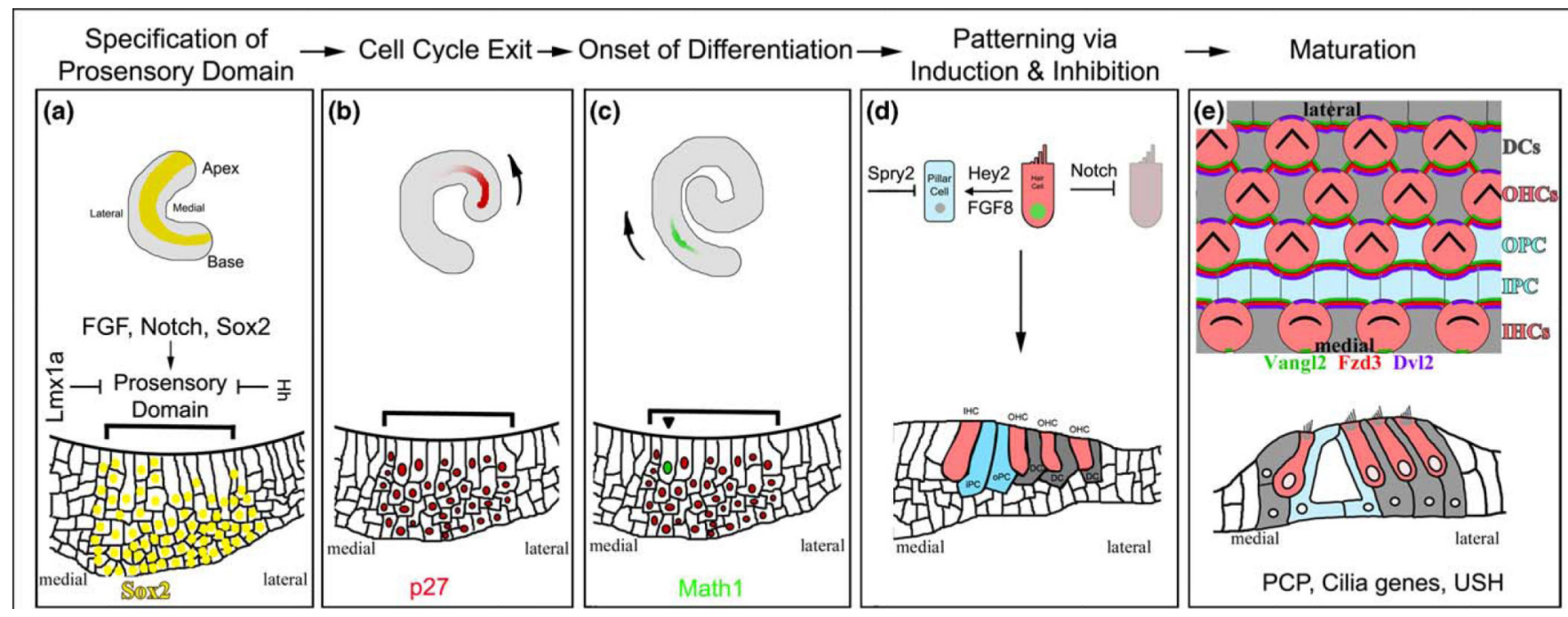

Figure 2.

The development of the auditory sense organ. (A) The cochlear duct begins as an expansion of the ventral-most portion of the otocyst. Initial specifications of prosensory domain most likely begin as soon as the cochlear duct is recognizable. The prosensory domain is further restricted to a group of cells on the floor of the cochlea duct (shown with bracket) by the action of Sox2, Notch and Hedgehog $(\mathrm{HH})$ signaling, and Lmx1a. Diagrams for the wholemount cochlea (top) and the cross-section of the cochlea at this stage highlight the expression of Sox 2 (yellow) in the prosensory domain. (B) The sensory precursor cells become postmitotic under the control of several cyclin-dependent kinase inhibitors, including p27. Cell cycle exit is initiated in the cells in the apical region and progresses toward the basal region, coinciding with the gradient of p27 onset in the cochlea. The arrow indicates the direction of onset of p27 and the gradient of cell cycle withdrawal along the longitudinal axis of the cochlear duct. (C) The first sign of differentiation within the postmitotic prosensory domain is the expression of the transcription factor Math1, which starts in the midbasal region and progresses toward both the apex and the base of the cochlea. There is also a second gradient along the medial-lateral axis of the cochlea from the inner to outer hair cells. The arrow indicates the longitudinal gradient of Math1 onset and hair cell differentiation. (D) Inductive and inhibitory signaling creates the correct cellular patterning of the organ of Corti. Much of this appears to be mediated by Notch signaling, which inhibits hair cell neighbors from adopting the same fate. Furthermore, the initial differentiation of the inner hair cells appears to direct the differentiation of other cells types, such as the Pillar cells (blue) through FGF8 and Hey2 in a Notch-independent manner. Sprouty 2 (SPY2) further restricts the differentiation of pillar cells. (E) During terminal differentiation and maturation, all cells in the organ of Corti coordinate their cellular morphologies under the regulation of the planar cell polarity (PCP) signaling pathway, which, in part, involves the asymmetric distribution of a core set of proteins (some examples are shown). The result of PCP signaling in the ear can be most clearly observed by the uniform orientation of the ' $\mathrm{V}$ '-shaped hair bundles on the apical surfaces of hair cells. In mice, late embryonic and early postnatal hair cell and supporting cell types all undergo 
morphological and maturational changes that ultimately result in a highly sensitive sensory structure that is functional by two weeks after birth. 